\title{
Higher than expected growth rate of the Endangered West African giraffe Giraffa camelopardalis peralta: a successful human-wildlife cohabitation
}

\author{
J. - P. Suraud, J. Fennessy, E. Bonnaud, A. M. Issa, H. Fritz and J. - M. Gaillard
}

\begin{abstract}
The West African giraffe is a genetically unique population represented only by the subspecies Giraffa camelopardalis peralta, categorized as Endangered on the IUCN Red List. These giraffes live outside protected areas, without natural predators and share their habitat with local people and their livestock. This study provides demographic data on this poorly studied megaherbivore and documents its recovery. We analysed the results of photo-identification censuses from 1996 to 1999 (count data) and from 2005 to 2008 (count and demographic data). From 1996 to 1999 the annual growth rate was c. $19 \%$ because of an unbalanced population structure after a period of severe poaching. From 2005 to 2008 an annual growth rate of c. $12-13 \%$ was estimated from both count data and demographic parameters. This value fits with the maximum growth rate calculated for a browser species based on the allometric relationship linking growth rate and body mass. During the period 2005-2008 adult and subadult females had a constant survival rate of 0.94 and a constant recapture rate of 0.97 . Annual calf survival rate was 1 . Observed sex ratio at birth was 0.57 and mean reproductive success was 0.257 . Generation time was estimated to be 9.66 years. This spectacular population growth was mostly attributed to the absence of predators and the ongoing monitoring to limit illegal hunting.
\end{abstract}

Keywords Capture-mark-recapture, demography, giraffe, Giraffa camelopardalis peralta, growth rate, population dynamics, survival

\footnotetext{
J.-P. SuRAuD*, H. FritZ and J.-M. GAILlaRd (Corresponding author) Laboratoire de Biométrie et Biologie Evolutive (UMR 5558), CNRS, Université Lyon 1, 43 bd 11 nov, F-69622 Villeurbanne Cedex, France. E-mail jean-michel.gaillard@ univ-lyon1.fr

J. FenNessy Giraffe Conservation Foundation, Purley, UK

E. BonNAud Ecology Systematics and Evolution, Paris Sud University, ORSAY Cedex, France

A.M. Issa Direction de la Faune, de la Chasse et des Aires Protégées, Ministère de l'Environnement et de la Lutte contre la Désertification, Niger

${ }^{\star}$ Also at: Association pour la Sauvegarde des Girafes du Niger, Niamey, Niger

Received 23 November 2010. Revision requested 17 February 2011.

Accepted 9 March 2011
}

\section{Introduction}

Since the beginning of the 2oth century the density $\checkmark$ and distribution of giraffe Giraffa camelopardalis populations has decreased across Africa (Sidney, 1965) to a total of c. 140,000 by the late 1990s (East, 1999). Giraffes are now thought to number $<80,000$ (unpubl. data from the international giraffe database). The population of the West African giraffe Giraffa camelopardalis peralta, a genetically unique subspecies represented only by this population, has also decreased (Brown et al., 2007; Hassanin et al., 2007).

During Palaeolithic times the giraffe ranged across West and North Africa, including the Mediterranean coastline (Mauny, 1957). In the early 2oth century the West African giraffe was found across the Sudano-Sahelian zone from Chad to Senegal. Poaching, habitat loss and fragmentation were the main drivers of their decline (Ciofolo, 1995).

Despite the implementation of an anti-poaching programme in the early 1980s (Pfeffer, 1981), the number of West African giraffes continued to decline. In 1996 the last 50 individuals of this population were concentrated close to Niamey, the capital of Niger (Ciofolo, 1998; Le Pendu \& Ciofolo, 1999). The Government of Niger made concerted efforts to enforce legislation preventing the illegal killing of giraffes, further supported by a community education and awareness campaign coordinated by PURNKO (Projet d'Utilisation des Ressources Naturelles de Kouré). Since 2000, with the additional help of ASGN (Association for Saving the Giraffes of Niger) and AVEN (Association pour la Valorisation de l'Ecotourisme au Niger; the giraffe guide association), poaching has almost ceased. Only three cases of poaching of giraffes were reported between 2005 and 2009. In 2008 the West African giraffe was categorized as Endangered on the IUCN Red List (Fennessy \& Brown, 2008).

In 2009 the West African giraffe numbered c. 220 individuals (Suraud, in press), living outside protected areas and without natural predators (i.e. lions Panthera leo), and thus sharing their habitat with local people and their livestock. This unique case of human-giraffe cohabitation enables giraffes to be individually monitored at close range with minimal flight response, and thus offers ideal conditions to study population dynamics and estimate the maximum population growth rate $(r$-max sensu Caughley, 1977) of this poorly studied megaherbivore (sensu Owen-Smith, 1988). 
Prior to this research most studies of giraffe population dynamics have focused on decreasing (Leuthold, 1978) or stable populations (Foster \& Dagg, 1972; Ngog Nje, 1983) and the maximum annual growth rate of a giraffe population was reported to be $6 \%$, in the Serengeti National Park (Pellew, 1983). The aims of our study were to (1) analyse the results of the various West African giraffe censuses from 1996 to 1999 (count data from photo-identification) and from 2005 to 2008 (both count and demographic data), (2) assess the structure of this population, and (3) estimate the demographic parameters of this recovering population.

\section{Study area}

The study area lies in the Sahel, with a mean total annual rainfall of $400-500 \mathrm{~mm}$. The Fakara Plateau (Kouré, Fandou), the North Dallol Bosso, and the Intermediate Zone are the three major areas of the West African giraffe's core range. Giraffes move across all three of these areas, and their presence appears to be predominantly associated with seasonal rainfall and availability of forage (Ciofolo, 1998; Le Pendu \& Ciofolo, 1999). The giraffes roam during the rainy season (June-October) onto the Fakara Plateau, and during the dry season (November-May) they return to the North Dallol Bosso where the vegetation is sparser but where species such as Faidherbia albida provide essential seasonal forage in the form of new leaves and pods. The Intermediate Zone, the area used between the rainy and dry seasons, is an important corridor for the seasonal migration of these giraffes (Le Pendu \& Ciofolo, 1999).

The plateau vegetation is composed of tiger bush and cultivated crops (e.g. millet, sorghum and beans). Tiger bush is a patterned vegetation community consisting of alternating bands of trees or shrubs separated by bare ground. Because of its organization and structure, tiger bush uses surface run-off optimally and is largely dominated by Combretaceae (Guiera senegalensis, Combretum micranthum, Combretum nigricans) mixed with Mimosaceae and Capparidaceae (Acacia ataxacantha, Acacia macrostachya, Dichrostachys cinerea, Boscia angustifolia, Boscia senegalensis; Saadou, 1996).

\section{Methods}

\section{Data collection}

We analysed the results of two series of censuses. The first was conducted from 1996 to 1999 by the PURNKO project (Ciofolo, 1998; Ciofolo et al., 2000), based on photoidentification. The second was conducted from 2005 to 2008 by ASGN in collaboration with the Niger Ministry of Environment, AVEN, the Arborescence Association (in 2007), the ECOPAS (ECOsystèmes Protégés en Afrique
Soudano Sahélienne) project, local foresters, Peace Corps volunteers, and international students (Suraud \& Dovi, 2006, 2007; Suraud, 2008, 2009). These latter censuses were improved by photo-identification, which allowed correcting for repeated observations of the same giraffes.

Censuses based on photo-identification were quasiexhaustive for this small population. We attempted to count every individual, developing an individual identity card, and determined the distribution of the population by sex and age classes. Photo-identification facilitated the building of individual capture-recapture histories, and thereby reliable estimates of age-specific survival rates. Then, using field-based estimates of reproductive parameters we used demographic models to estimate population growth independently from annual counts (Caswell, 2001).

Each census was conducted annually, during the rainy season, because the giraffes aggregated during this period in the Kouré and Fandou plateaus, $60 \mathrm{~km}$ east of Niamey. The plateaus were surveyed using a systematic sampling design: annually from 2005 to 2008 up to three teams in 4 -wheel drive vehicles identified every giraffe present until no new giraffes were detected. The teams involved up to 22 people for c. 45 cumulative days every year from July to September. The photo-identification album was regularly updated and used to assess whether a given giraffe had been previously recorded or was a new individual.

From three to six age classes have been used to determine a giraffe's age (Foster \& Dagg, 1972; Leuthold, 1978; Pellew, 1983; Fennessy, 2003). We used four age classes to standardize data. Long-term survey data allowed us to have information about most of the calves born between and within the two census periods (1996-1999 and 2005-2008). The first age-class included juveniles $<6$ months of age characterized by a height of c. $2 \mathrm{~m}$. The second included young from 6 (>2 m tall) to 18 months (up to $3 \mathrm{~m}$ tall) of age; by the age of 12-18 months young may be separated from their mothers. Although it included the second half of the juvenile period and the first half of the yearling period (sensu Gaillard et al., 2000), we called this class yearling. The third corresponded to subadults from 18 months to 4 years of age; secondary sexual traits such as the small central ossicone are characteristic features of subadult males. The fourth included adults $>4 \mathrm{~m}$ tall; the central ossicone of the adult males is well developed.

As the pelage pattern of a giraffe does not change during its life the form of the spots along the neck has been used to identify individuals (e.g. Innis, 1958; Foster, 1966; Leuthold, 1978; Fennessy, 2003). Although the colour intensity of pelage may change over time and ossicones may increase in size, especially in males (Dagg \& Foster, 1982; Seymour, 2002), an individual can be reliably recognized when observed at frequent intervals. In our study photographs of the left and right profiles of each giraffe were taken to 
facilitate identification of individuals using their unique pattern of spots.

Individual identification sheets were completed for each giraffe. Recorded data included the name, age class, sex and reproductive status. Prominent scars, ossicone size or shape, and pelage colour were also described. To identify each individual reliably remarkable spots were highlighted on the photographs. This method enabled continuous updating of the giraffe identification sheets as more images were obtained or new recognizable features observed (Fennessy, 2003).

\section{Data analysis}

We calculated the mean annual population growth rate for both census periods (1996-1999 and 2005-2008) and compared estimates obtained from the annual counts and from a demographic model based on the 2005-2008 data (Table 1). Demographic parameters, including age-specific survival rates and reproductive success, were estimated for 2005-2008. The generation time, a measure of the speed of the life history (Gaillard et al., 2005), was also calculated. We plotted log-transformed annual counts in relation to time. The population growth rate $(r)$ was estimated from the time series of annual counts as the regression coefficient of the linear model of the log-transformed population size against time, where $\lambda$ is the log-transformed $r$ (Lebreton \& Millier, 1982). Regression analysis was performed with $R$ v. 2.8.1 (R Development Core Team, 2008).

We used capture-mark-recapture models (Lebreton et al., 1992) to estimate female survival rates using $M$ SURGE (Choquet et al., 2004). Surveys included 45 females marked as adults and 39 females marked as subadults between 2005 and 2008. We checked for the goodness-of-fit of data to the fully time-dependent Cormack-Jolly-Seber model using U-CARE (Choquet et al., 2005). Using this model as a starting point we tested for time-dependence in survival and resighting probabilities for both adult and subadult females.

We assumed that the availability of males did not limit female reproduction and used female-based models to estimate population growth rates (Caswell, 2001). Firstly, fecundity was measured as the number of females produced per female (for an annual maximum of 0.5 , assuming a sex ratio of $1: 1$ at birth). Then, we considered the observed sex ratio, which was biased in favour of males among calves ( 56 out of the 99 calves observed were males, leading to a male/female sex ratio of 0.57 ). We then built a Leslie matrix (Leslie, 1945), which is a deterministic, age-structured and female-based model commonly used for management of ungulate populations (Eberhardt, 1991; Gaillard \& Yoccoz, 2003). We used the estimates of survival and reproductive success (measured as the product of juvenile survival and fecundity) in terms of female offspring only, for each age
TABLE 1 The giraffe Giraffa camelopardalis peralta population in Niger, by sex and age classes, from 2005 to 2008 (2005 data: Suraud \& Dovi, 2006; 2006 data: Suraud \& Dovi, 2007; 2007 data: Suraud, 2008; 2008 data: Suraud, 2009).

\begin{tabular}{llccrr}
\hline Age & Sex & 2005 & 2006 & 2007 & 2008 \\
\hline Calf & Female & 2 & 5 & 3 & 4 \\
& Male & 7 & 9 & 15 & 7 \\
Yearling & Female & 9 & 12 & 8 & 21 \\
& Male & 8 & 11 & 5 & 23 \\
Subadult & Female & 11 & 10 & 16 & 11 \\
& Male & 5 & 11 & 14 & 12 \\
Adult & Female & 57 & 50 & 59 & 69 \\
& Male & 36 & 36 & 41 & 45 \\
Total & & 135 & 144 & $164^{1}$ & $193^{2}$ \\
\hline
\end{tabular}

${ }^{1}+3$ calves of unknown sex

${ }^{2}+1$ calf of unknown sex

class (Largo et al., 2008). We assigned a value of 1 for juvenile survival as all female calves survived during their first year of life. While this is an overestimation of juvenile survival it did not influence the estimate of population growth rate because calves that died before being detected in the field were assumed not to have been conceived, so that the measure of recruitment was accurate irrespective of the magnitude of calf mortality. However, calf mortality was probably very low because most dead giraffes were recovered from detailed Ministry of Environment-ASGN records of dead giraffes. When a giraffe died local foresters, alerted by villagers, informed the Ministry of Environment, and a dedicated team identified the dead animal. Eleven giraffes were recorded dead during 2005-2008. Among the females none were juveniles or yearlings. We assume records of giraffe deaths were exhaustive, in particular in the species' core range. Thus, as for juveniles, we assigned a value of 1 to yearling survival because all yearling females survived from 2005 to 2008, according to censuses and records of dead giraffes. For the other age classes we assigned a constant value of 0.945 to survival (see Results). We calculated generation time as the inverse of the elasticity of recruitment (Brooks \& Lebreton, 2001).

\section{Results}

The West African giraffe population increased markedly during both census periods: $\lambda$ was estimated to be $1.193 \pm$ SE $0.0356\left(r^{2}=0.976\right)$ and $1.130 \pm$ SE $0.03684\left(r^{2}=0.947\right)$ during the 1996-1999 and 2005-2008 periods, respectively (Fig. 1). For adult females the best model included a constant survival (0.944 \pm SE 0.0225$)$ and a constant recapture rate (0.975 \pm SE 0.0172; Akaike Information Criterion, AIC, of 75.092 for the constant model vs 78.417 for the model with time-dependent resighting probability, and 76.190 for the model with time-dependent survival). For subadult females, 


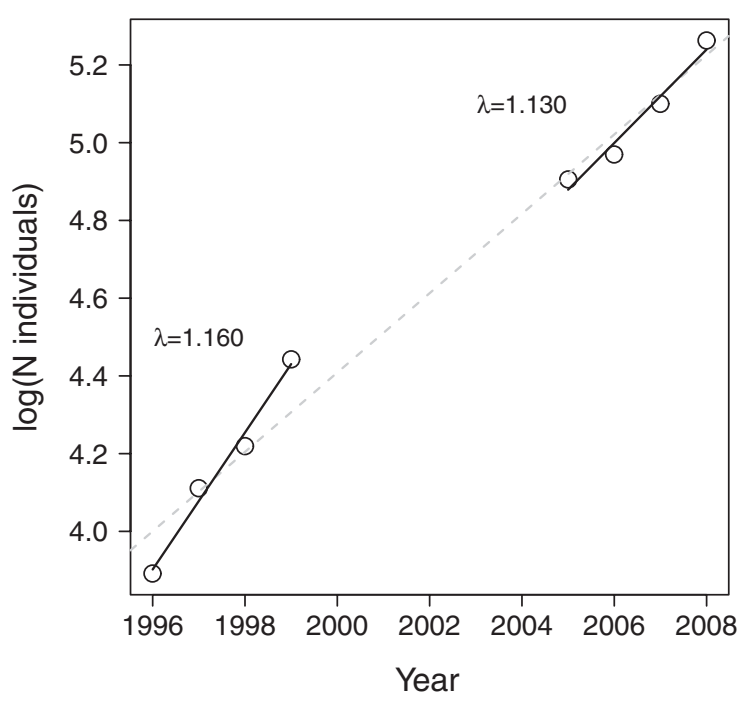

FIG. 1 Log-transformed annual counts of giraffe Giraffa camelopardalis peralta in Niger from 1996 to 2008. Data from 1996 to 2000: Ciofolo et al. (2000); 2005 data: Suraud \& Dovi (2006); 2006 data: Suraud \& Dovi (2007); 2007 data: Suraud (2008); 2008 data: Suraud (2009). See text for details of the regression analyses.

the same simplest model best fitted the data, with a constant survival $(0.945 \pm \mathrm{SE} 0.0226)$ and a constant recapture rate (0.979 \pm SE 0.0194; AIC of 58.364 for the constant model vs 62.135 for the model with time-dependent resighting probability, and 60.175 for the model with time-dependent survival). From the analysis of giraffes marked as subadults there was no difference in yearly survival between subadults and adults (0.945 \pm SE 0.026 vs $0.944 \pm$ SE 0.0225 , for subadults and adults, respectively). Therefore, we retained a constant survival of 0.945 for both adult and subadult females.

Between 2005 and 2008 the juvenile and yearling survival rates were 1 . Reproductive success and fecundity were therefore identical. Considering a balanced sex ratio at birth the reproductive success was 0.312 . When using the observed sex ratio at birth (0.57) the reproductive success was a little lower, at 0.257 . The reproductive success of giraffe females in Niger averaged 0.257 from 2005 to 2008 , being higher in 2006 (0.34) and 2008 (0.309) than in 2005 (0.193) and 2007 (o.186).

The Leslie matrix estimate of $\lambda$ was 1.135 using a balanced sex ratio among calves and 1.112 when the observed biased sex ratio towards male calves was included. The elasticity of $\lambda$ to changes of recruitment was 0.103 , and therefore the generation time was 9.66 years. The elasticity of $\lambda$ to changes in adult survival was 0.896 .

\section{Discussion}

For adult females a model of constant survival and capture probabilities best described the data collected for the West
African giraffe in Niger. The high and constant recapture probability indicated that quasi-exhaustive counts were performed from 2005 to 2008. Such quasi-exhaustive counts were possible because the absolute number of giraffes was relatively low, the population was concentrated within a limited area during the counting period, and field teams worked until no new giraffes were detected.

Reproductive success is high in this population as the juvenile survival is 1 and all adult females reproduce regularly. Nevertheless, the reproductive success calculated using the observed sex ratio biased in favour of male calves was, as expected, lower than the reproductive success calculated with a balanced sex ratio. An unbalanced sex ratio among calves has been observed in other giraffe populations (Innis, 1958; Cooper, 1980) and should be taken into account when studying giraffe population dynamics. An unbalanced sex ratio in favour of females was observed for the adult and subadult classes of the West African giraffe during 1996-1999 and 2005-2008. In 1996 the population structure was mostly driven by the impacts of hunting, and the observed female-biased sex ratio in adult and subadult giraffes was probably caused by poaching pressure on males. During 2005-2008 the unbalanced sex ratio in favour of females in the adult and subadult age classes probably corresponded to a lower survival of males than females, as expected in a dimorphic ungulate species (Toïgo \& Gaillard, 2003; Isvaran \& Clutton-Brock, 2007).

Table 1 shows that male calves in $2006(n=9)$ were not all included in the yearling age class the following year $(\mathrm{n}=5)$. We based age determination on observations. Two calves recorded in 2006 at c. 6 months of age were classified as subadults ( 18 months to 4 years of age) in 2007 instead of as yearlings (6-18 months). Others calves observed in 2006 were not included in 2007 as yearlings because they were not seen in 2007 but were seen again in 2008, providing evidence they were alive but not observed in 2007 .

The population growth rate estimated from the demographic model including the offspring sex ratio biased in favour of males was lower than that estimated from counts, as expected when using a female-based model (Owen-Smith, 1988). Using a balanced sex ratio the growth rate estimated with the demographic model was close to the growth rate estimated from counts of giraffes, as expected with quasi-exhaustive counts with a high detection probability (0.94). As suggested by Largo et al. (2008), when counting is less exhaustive population growth rates estimated from demographic models can differ markedly from growth rates calculated from annual counts. In our particular case the relatively low number of individuals means that even a low number of undetected individuals can cause a large error in estimated growth rates from counts. We thus recommend using population growth obtained from demographic models at low population size. 
Why was there such a high growth rate from 1996 to 2008 ?

As expected in a long-lived species the elasticity of $\lambda$ to survival change was high (0.90). A given variation in survival after 1 year of age would thus have almost nine times more impact on $\lambda$ than the same variation in recruitment. Predation is often the principal factor affecting survival in African ungulates (Owen-Smith et al., 2005). For the giraffe, predation predominantly affects young. As a result the limiting factor for giraffe population growth rate when the illegal hunting of adult giraffes is prevented is juvenile survival. In a 3-year study Foster \& Dagg (1972) reported a high mortality rate in juveniles in Nairobi National Park, Kenya, where c. $75 \%$ of young died within their first year of life, with a peak in mortality during the first months of life. In a study based on a smaller sample size Pellew (1983) found that first year mortality of giraffes in the Serengeti National Park was c. $60 \%$, with a peak in mortality in the first months of life. Estimated adult mortality in this Park was $5-10 \%$, leading to population growth of $6 \%$. The estimated annual growth rate of the West African giraffe population between 1996 and 2008 was much higher. Such strong population recovery can be explained by the absence of predators and by severely limited illegal hunting, probably corresponding to the $r$-max of the giraffe (sensu Caughley, 1977). Recruitment in the Niger population was high. However, if we compare the Niger population with that in the Serengeti National Park (Pellew, 1983) the observed proportion of first year calves are similar (15\% in Serengeti vs $16 \%$ in Niger) despite a much lower growth rate in the Serengeti. Taking into account the high first year mortality in the Serengeti it is likely that there was an overestimation there of the proportion of first year calves.

During 1996-1999 $\lambda$ was higher than the expected $\lambda$-max of a browser of the giraffe's size. A particularly high growth rate could have taken place during 1996-1999 because of an unbalanced population structure, including a high proportion of adult females ( $47 \%$ in 1996) and a low number of individuals, thus facilitating a rapid increase in the population. Such deviations from the asymptotic age structure are widespread in vertebrate populations and, although they are generally neglected, have to be accounted for (Koons et al., 2005).

An increasing ungulate population of a browser species of the size of the giraffe is expected to have a $\lambda$-max of 1.138 based on the allometric relationship linking growth rate and size (Gaillard et al., 2008). This value is close to the $\lambda$ estimated for 2005-2008 based on count and demographic data. This high value of $\lambda$ matches the $\lambda$-max expected from the allometric relationship established using browser species spanning a large range of sizes. This suggests that megaherbivores may not have allometric relationships that are different from smaller species. Our study demonstrates that under favourable conditions a population of giraffes can reach the theoretical maximum growth rate expected for its size and diet. Likewise, considering the allometric relationship linking generation time and body mass specific to large herbivores with a browser diet type (Gaillard et al., 2008), the predicted value of generation time (10 years) is also close to that observed (9.66 years). Foley \& Faust (2010) reported the rapid growth of an elephant population under good environmental conditions after being released from the stress of heavy illegal hunting (mean growth rate of $6.8 \%$ observed over 13 years, close to the maximum of $7 \%$ calculated by Calef, 1988). These studies indicate that megaherbivores can grow at higher rates than previously expected, and that allometric relationships could be extrapolated to large species, contrary to what was suggested before high quality empirical data were available (Owen-Smith, 1988).

\section{Is the present population growth sustainable?}

Niger is faced with a spectacular recovery of the West African giraffe population after a period of high illegal hunting, with the population growing since 1996 when poaching was controlled. We recorded an annual growth rate of c. $12-13 \%$ from 2005 to 2008 , the highest value ever reported for the giraffe. Even though the population is still increasing the area covered by tiger bush, which is the major rainy season habitat and forage for the giraffe, is decreasing as a result of increasing agriculture and wood cutting (Morou et al., 2009). Between 1975 and 2002 agricultural activities within the range of this giraffe subspecies increased from 50 to $80 \%$ of the area (Abdou, 2005). With an increase of the giraffe population occurring simultaneously with the ongoing destruction of their habitat, human-giraffe conflicts are expected to increase (Leroy et al., 2009). The giraffes have adapted their feeding behaviour and have been reported to damage local crops such as beans and mangos (Leroy et al., 2009; Morou et al., 2009). In a poor country these conflicts are a potential threat to the longterm sustainability of the giraffe population. In the current ecological and economic situation the high annual growth rate observed in the recent past is unlikely to persist. We can expect a potential split of the population into several subpopulations as giraffes seek more favourable habitats; i.e. with greater food availability and quality and lower human disturbance. Although the carrying capacity of the giraffe core range is difficult to assess, with decreasing food resources and increasing human disturbance we expect it will decrease. This will probably stimulate giraffes to settle outside their current core area. Exploratory trips have been recorded, with some giraffes observed far from their core range; e.g. three herds of giraffes were observed in 2008 close to the Mali border c. $150 \mathrm{~km}$ north of the giraffe core range. 
In seeking new areas giraffes are likely to be more vulnerable to hunters, especially in neighbouring Mali or Nigeria. In 2000 all the five giraffes observed in Mali were poached (I. Ciofolo, pers. comm.). In 2007 two giraffes were killed in Nigeria soon after crossing the border (I. Ciofolo, pers. comm.).

Further detailed monitoring, assessment of habitat use and mitigation of human-giraffe conflicts should allow us to propose effective management and a strategy for the longterm conservation of the West African giraffe. The ongoing monitoring based on photo-identification, which provided the basis of our analyses, will facilitate future assessments of whether the region can sustain a growing population of this subspecies of giraffe.

\section{Acknowledgements}

Field work during 2005-2008 and data analysis were facilitated by collaboration with the Directorate of the Fauna, Hunting and Protected Areas of the Niger Environment Ministry, ASGN, AVEN, the ECOPAS project, students from Abdou Moumouni University (Niger) and from Université de Québec à Montréal (Canada), and by the financial help of Prince Albert II de Monaco Foundation, Giraffe Conservation Foundation (financial and scientific support), Doué la Fontaine zoo, South Lakes Wild Animal Park, Nature \& Découverte Foundation, Arborescence Association, CEPA association, Touroparc, Cerza Park, African Wildlife Foundation, and Mohamed bin Zayed Foundation.

\section{References}

A вdou, N. (2005) Etude prospective des sites de formations contractées dans certaines zones de l'Ouest nigérien (Fandou et Tombo) dans la perspective de la décongestion de la zone de Kouré habitat actuel des Girafes. MSc thesis. Niamey University, Niamey, Niger.

Brooks, E.N. \& LeBreton, J.D. (2001) Optimizing removals to control a metapopulation: application to the yellow legged herring gull (Larus cachinnans). Ecological Modelling, 136, 269-284.

Brown, D.M., Brenneman, R.A., Koepfli, K.P., John, P., Pollinger, J.P. \& MilÁ, B. et al. (2007) Extensive population genetic structure in the giraffe. BMC Biology, 5, 57 .

Calef, G. (1988) Maximum rate of increase in the African elephant. African Journal of Ecology, 26, 323-327.

Caswell, H. (2001) Matrix Population Models, 2nd edition. Sinauer Associates, Sunderland, USA.

Caughley, G. (1977) Analysis of Vertebrate Populations. Wiley, London, UK.

Choquet, R., Reboulet, A.M., Lebreton, J.D., Gimenez, O. \& PRADEL, R. (2005) U-CARE 2.2 User's Manual. CEFE/CNRS, Montpellier, France.

Choquet, R., Reboulet, A.M., Pradel, R., Gimenez, O. \& Lebreton, J.D. (2004) User's Manual for M-SURGE 1.4. Mimeographed Document. CEFE/CNRS, Montpellier, France.
Ciofolo, I. (1995) West Africa's last giraffes: the conflict between development and conservation. Journal of Tropical Ecology, 11, 577-588.

Ciofolo, I. (1998) Rapport final de mission du Projet d'Utilisation des Ressources Naturelles de Kouré et du Dallol Bosso Nord. PURNKO report, Niamey, Niger.

Ciofolo, I., Le Pendu, Y. \& Gosser, A. (2000) Les girafes du Niger, dernières girafes d'Afrique de l'Ouest. Revue d'Ecologie (La Terre et La Vie), 55, 117-128.

Cooper, T.G. (1980) A Brief Summary of Results by Quarterly Game Counts Conducted in the Central Section of Skeleton Coast Park for the Period October 1978-December 1980. Unpublished Report. Department of Agriculture and Nature Conservation, Windhoek, SWA/Namibia.

DAGG, I. \& Foster, J. (1982) The Giraffe: Its Biology, Behaviour and Ecology. Krieger Publishing Co., Malabar, USA.

EAst, R. (1999) African Antelope Database 1998. IUCN/Species Survival Commission Antelope Specialist Group, IUCN, Gland, Switzerland.

Eberhardt, L. (1991) Models of ungulate population dynamics. Rangifer, 7, 24-29.

Fennessy, J.T., Leggett, K.E.A. \& Scheider, S. (2003) Distribution and status of the desert-dwelling giraffe (Giraffa camelopardalis angolensis) in north-western Namibia. African Zoology, 38, 184-188.

Fennessy, J. \& Brown, D. (2008) Giraffa camelopardalis ssp. peralta. In IUCN Red List of Threatened Species v. 2012.1. Http://www. iucnredlist.org [accessed 21 June 2010].

Foley, C. \& FAUST, L. (2010) Rapid population growth in an elephant population recovering from poaching in Taranguire National Park, Tanzania. Oryx, 44, 205-212.

Foster, J. (1966) The giraffe of Nairobi National Park: home range, sex ratios, the herd and food. East African Wildlife Journal, 4, 139-148.

Foster, J. \& DAGG, I. (1972) Notes on the biology of the giraffe. East African Wildlife Journal, 10, 1-16.

Gaillard, J.M., Duncan, P., van Wieren, S.E., Loison, A., Klein, F. \& Maillard, D. (2008) Managing large herbivores in theory and practice: is the game the same for browsing and grazing species? In The Ecology of Browsing and Grazing (eds I.J. Gordon \& H.H.T. Prins), pp. 293-307. Springer-Verlag, Berlin and Heidelberg, Germany.

Gaillard, J.M., Festa-Bianchet, M., Yoccoz, N.G., Loison, A. \& Tolgo, C. (2000) Temporal variation in fitness components and population dynamics of large herbivores. Annual Review of Ecology and Systematics, 31, 367-393.

Gaillard, J.M. \& Yoccoz, N. (2003) Temporal variation in survival of mammals: a case of environmental canalization? Ecology, 84, 3294-3306.

Gaillard, J.M., Yoccoz, N.G., Lebreton, J.-D., Bonenfant, C., Devillard, S., Loison, A. et al. (2005) Generation time: a reliable metric to measure life history variation among mammalian populations. The American Naturalist, 166, $119-123$.

Hassanin, A., Ropiquet, A., Gourmand, A.L., Chardonnet, B. \& Rigoulet, J. (2007) Mitochondrial DNA variability in Giraffa camelopardalis: consequences for taxonomy, phylogeography and conservation of giraffes in West and Central Africa. Comptes Rendus Biologies, 330, 265-274.

Innis, A. (1958) The behaviour of the giraffe, Giraffa camelopardalis, in the eastern Transvaal. Proceedings of the Zoological Society of London, 131, 245-278.

Isvaran, K. \& Clutton-Brock, T.H. (2007) Ecological correlates of extra-group paternity in mammals. Proceedings of the Royal Society of London. Series B, Biological Sciences, 274, 219-224. 
Koons, D.N., Grand, J.B., Zinner, B. \& Rockwell, R.F. (2005) Transient population dynamics: relations to life history and initial population state. Ecological Modelling, 185, 283-297.

Largo, E., Gaillard, J.M., Festa-Bianchet, M., Tolgo, C., Bassano, B., Cortot, H. et al. (2008) Can ground counts reliably monitor ibex Capra ibex populations? Wildlife Biology, 14, 489-499.

Lebreton, J.D., Burnham, K.P., Clobert, J. \& Anderson, D.R. (1992) Modelling survival and testing biological hypotheses using marked animals: a unified approach with case studies. Ecological Monographs, 62, 67-118.

Lebreton, J.-D. \& Millier, C. (1982) Modèles dynamiques déterministes en biologie. Masson, Paris, France.

Le Pendu, Y. \& Ciofolo, I. (1999) Seasonal movements of giraffes in Niger. Journal of Tropical Ecology, 15, 341-353.

Leroy, R., De Visscher, M.N., Halidou, O. \& Boureïma, A. (2009) The last African white giraffes live in farmers' fields. Biodiversity and Conservation, 10, 2663-2677.

Leslie, P. (1945) On the use of matrices in population mathematics. Biometrika, 33, 182-212.

Leuthold, B.M. (1978) Ecology of the giraffe in Tsavo East National Park, Kenya. African Journal of Ecology, 16, 1-20.

MaUnY, R. (1957) Répartition de la grande faune éthiopienne du NordOuest africain du Paléolithique à nos jours. Bulletin IFAN, 7, 246278.

Morou, B., Ambouta, J.M.K., Mahamane, A. \& Oumani, A. (2009) Interaction entre hommes et girafes dans la zone de distribution de la girafe au Niger. Annales de l'Université Abdou Moumouni, Niamey, Niger.

NGog NJE, J. (1983) Structure et dynamique de la population de girafes du parc National de Waza, Cameroun. Revue d'Ecologie (La Terre et La Vie), 37, 1-20.

Owen-Smith, N. (1988) Megaherbivores: The Influence of Very Large Body Size on Ecology. Cambridge University Press, Cambridge, UK

Owen-Smith, N., Mason, R.R. \& Ogutu, J.O. (2005) Correlates of survival rates for ten African ungulate populations: density, rainfall and predation. Journal of Animal Ecology, 74, 774-788.

Pellew, R. (1983) The giraffe and its food resource in the Serengeti. Response of the giraffe population to changes in the food supply. African Journal of Ecology, 21, 269-283.

Pfeffer, P. (1981) Les dernières girafes occidentales, une action exemplaire du WWF. Panda, 6, 9-10.

R Development Core Team (2008) R: A Language and Environment for Statistical Computing. R Foundation for Statistical Computing, Vienna, Austria.

SAADou, M. (1990) La végétation des milieux drainés nigériens à l'Est du fleuve Niger. PhD thesis. University of Niamey, Niamey, Niger.
Seymour, R. (2002) Patterns of subspecies diversity in the giraffe, Giraffa camelopardalis (L. 1758): comparison of systematic methods and their implications for conservation policy. $\mathrm{PhD}$ thesis. Institute of Zoology, Zoological Society of London, London, UK, and The Durrell Institute for Conservation and Ecology, University of Kent, Canterbury, UK.

Sidney, J. (1965) The past and present distribution of some African ungulates. Transactions of the Zoological Society of London, 30, 139168.

Suraud, J.P. (2008) Giraffes of Niger, 2007 census and perspectives. Bi-Annual Newsletter of the International Giraffe Working Group, 2(1), 4-7.

SURAUD, J.P. (2009) 2008 giraffes in Niger! Bi-Annual Newsletter of the International Giraffe Working Group, 3(1), 32-33.

SURAUD, J.P. (in press) Giraffe of Niger census 2009, end of the spectacular recovery? Bi-Annual Newsletter of the International Giraffe Working Group.

SuRAud, J.P. \& Dovi, O. (2006) The giraffes of Niger are the last in all West Africa. IUCN Bi-Annual Newsletter of the International Giraffe Working Group, 1(1), 8-9.

Suraud, J.P. \& Dovi, O. (2007) Giraffes of Niger-2006 census. Bi-Annual Newsletter of the International Giraffe Working Group, $1(2), 12-13$.

Tolgo, C. \& Gaillard, J.M. (2003) Causes of sex-biased adult survival in ungulates: sexual size dimorphism, mating tactic or environment harshness? Oikos, 101(2), 376-384.

\section{Biographical sketches}

JEAN - PATRICK SURAUD's research focuses on wildlife conservation. He was the ASGN scientific advisor (2007-2010), is a Giraffe Conservation Foundation research associate and an International Giraffe Working Group member. J ULIA N FENNeSSY is Director of the Namibia Nature Foundation, Chair of the IUCN Species Survival Commission Antelope Specialist Group International Giraffe Working Group, and Founding Trustee of the Giraffe Conservation Foundation. ElSA BONnAUD works on food webs on island ecosystems, and especially on biotic interactions between invasive species and native species. Aвdou Malam Issa, a Forestry engineer, is the Fauna, Hunting and Protected Areas Director of the Niger Environment Ministry. Hervé Fritz's research interest focuses on the ecology of vertebrate herbivores, addressing both theoretical and applied management questions. JEAN-Michel GaILlard's research focuses on population dynamics of large herbivores and life history evolution, from theoretical matters to applied population management. 